\title{
HEMIPLEGIA ESPÁSTICA PURA DE ORIGEM PIRAMIDAL
}

\author{
RICARDO DE OLIVEIRA SOUZA \#- DAYSE L, GUSMAOO * \\ WAGNER MARTIGNONI DE FIGUEIREDO *** - ANTONIO C, GOULART DUARTE :**
}

\begin{abstract}
RESUMO - Três pacientes acometidos de hemiplegia espástica pura apresentaram, à tomografia computadorizada, imagens hipodensas envolvendo regiōes dos hemisférios cerebrais hoje identificadas como locais de passagem dos feixes córtico-nuclear e piramidal. Em nenhum deles se registraram alteraçōes de forma, latência e amplitude dos potenciais evocados sômato-sensitivos. Com base nestes casos e em outros idênticos, recolhidos da literatura, reafirmamos a validade anátomo-clínica da síndrome piramidal, constituída de paresia, hiperreflexia, espasticidade e sinal de Babinski. o reconhecimento da existência de sindromes piramidais deficitárias, levou-nos a postular a heterogeneidade anatômica e funcional do feixe piramidal, através do conceito de «controle funcional diferencials. Aparentemente, estas conclusões se aplicam integralmente apenas ao ser numano.
\end{abstract}

\section{Pure spastic hemiplegia of pyramidal origin}

SUMMARY - The relationship between the interruption of the human pyramidal tract and its attendant clinical manifestations has been a matter of concern to neurologists and neurosurgeons for over a century. We presently report three cases of unilateral pyramidal tract ischemic lesions within the cerebral hemispheres who presented with a contrulateral pure spastic hemiplegia syndrome. In none could we find any disturbance in the somatosensitive evoked potentials of the four limbs. The review of some cases on record since the time of Charcot and Erb has made it clear that the pyramidal syndrome is a valid clinical concept which should be qualified according to the particular animal species one is referring to. In man, it manifests itself hy paresis, hyperactive muscular reflexes, spasticity and Babinski sign. Based on this evidence we propose the idea of a «differential control» exerted by the pyramida? tract upon the segmental neuronal pool as its key mode of normal functioning.

A hemiplegia representa um dos sinais cardinais da doença neurológica no homem. A questão da sede das lesões responsáveis por sua ocorrência pôde ser enfocada sob novo ângulo, depois da descrição da hemiplegia motora pura de origem vascular, por Fisher e Curry, em 196530 . Segundo esses autores, "uma hemiplegia motora pura (...) resulta de infarto no braço posterior da cápsula interna ou na basis pontis...". Desde então, inúmeras publicações têm enfatizado a multiplicidade de locais no interior do sistema nervoso central (SNC), cuja lesão se exterioriza por hemiplegia motora pura (HMP). De modo geral, para que aconteça, parece necessário $\mathrm{e}$ suficiente que $\mathrm{a}(\mathrm{s})$ lesão(ões) responsável(is) se inclua(m) nos limites da extensa área longitudinal com formato de pirâmide invertida, cuja base, aplanada no sentido ântero-posterior, é representada pelo córtex precentral e o ápice, truncado, pelas pirâmides bulbares. A hemiplegia, em tais casos, acomete o dimídio corporal contralateral à lesão encefálica e, a rigor, na maior parte das vezes, não se associa a espasticidade em grau significativo, sendo comum, todavia, acompanhar-se de sinal

* Serviço de Neurologia (Prof. Dr. Helcio Alvarenga) e ** Serviço de Clínica Médica III (Prof. Dr. Omar da Rosa Santos), Hospital Universitário Gaffrée e Guinle, UNI-RIO: * Serviço de Neurologia (Dr. Nunjo Flnkel), Santa Casa de Misericórdia do Río de Janeiro. 
de Babinski e hiperreflexia muscular de intensidade variável. A ausência de espasticidade em pacientes acometidos de HMP já havia sido assinalada por diversos autores, em especial por Barré 6 , ao descrever a sindrome piramidal deficitária, com o que buscou isolar o elemento paralítico propriamente dito da hemiplegia e distingui-lo uos sinais de irritação, isto é, da espasticidade, conforme hoje os chamariamos. $O$ estudo das manifestações clinicas provocadas por lesōes anatômicas discretas do SNC foi em multo facilitado pelas modernas técnicas diagnósticas de neuroimagem, inauguradas com a tomografia computadorizada (TC). Em geral, os infartos capsulares que se manifestam por $\mathrm{HMH}^{\prime}$ assumem à $\mathrm{T}^{\prime} \mathrm{C}$ dois aspectos distintos 40,43,54,63, na região do braço posterior da cápsula interna, correspondendo aos padrões anatômicos classicamente descritos por Fisher e Curry em material de necrópsia. $O$ mais freqüente, a lacuna típica, consiste em infarto pálido-capsular, tende a assumir forma arredondada e situa-se no território de distribuiçăo da artéria coróide anterior. $O$ segundo, a lacuna gigante, consiste em lesão putâmino-cápsulo-caudada que, em cortes coronais, se dispốe como bloco de tecido isquêmico com forma semilunar, na altura da junção da cápsula interna com a coroa radiada, no território de irrigação de um dos ramos lentículo-estriados mais laterais e maiores, provenientes da artéria cerebral média. Nos pacientes que apresentam infartos lacunares, na cápsula interna ou na base da protuberância, a recuperação gradual da hemiplegia é a regra e esse fator prognóstico representa um dos principais critérios para o agrupamento em separado de tais pacientes, dada a benignidade de sua condição 16. Por outro lado, nas hemiplegias em que se instala a atitude de Wernicke-Mann, com acentuada contratura espástica dos músculos paréticos, o déficit motor, além de persistente, costuma acompanhar-se de sinais adicionais de comprometimento cortical ou de vias sensitivo-sensoriais que os excluem do grupo puro das hemiplegias motoras. A esses casos correspondem lesões hemisféricas de natureza variada. Quando isquêmicas, conformam-se ao padrăo dos infartos extensos, não lacunares.

Com base em casos publicados mais recentemente, tornou-se possivel o mapeamento anátomo-clínico dos locais do SNC cuja lesão se exterioriza por HMP. Estes locais coincidem com a origem e o trajeto, nos hemisférios cerebrais e no tronco cerebral, dos feixes descendentes que partem do córtex precentral de cada lado 12 e cujas fibras remanescentes irão constituir, caudalmente, as pirâmides bulbares.

A posição do feixe piramidal (e córtico-nuclear) na cápsula interna merece destaque, por causa dos casos clínicos que relataremos. Em 1962, Hirayama et al.37 publicaram os resultados das necrópsias realizadas em três pacientes com esclerose lateral amiotrófica. Na cápsula interna, observaram degeneração conspicua das fibras de grande diâmetro (acima de $8 \mu$ ) do fejxe piramidal, que se situava em "área ligejramente posterior - a terceira região a partir da extremidade anterior (do braço posterior), quando o braço posterior é dividido em quatro partes iguais - em oposiçăo à extremidade posterior do globus pallidus". Essas conclusões coincidem com as de Brion e Guiot 11, publicadas dois anos mais tarde e fundamentadas em premissas metodológicas e material de exame anatômico diferentes. A anatomia do feixe piramidal em sua passagem pela cápsula interna foi igualmente estudada por Ross 56 . Seus resultados confirmam os precedentes e enfatizam a existência de fator anatômico de grande utilidade para a compreensão de determinadas manifestaçōes motoras deficitárias em lesões hemisféricas: ". . o feixe piramidal humano não mantém posição fixa na cápsula interna. Devido a um fenômeno de deslocamento (ântero-) posterior, o feixe (...) reside na metade anterior do braço posterior da cápsula interna rostral e na metade posterior do braço posterior, na cápsula interna caudal". Portanto, diversos autores têm concordado quanto a situação anatômica precisa do feixe piramidal e, correlativamente, quanto a situação das lesōes responsáveis pelo elemento deficitário das hemiplegias cruzadas. $O$ mesmo não se deu em relação às lesōes que, além do déficit motor, se acompanham de espasticidade, talvez pelo fato de que tais hemiplegias espásticas se associem de outros sinais de lesão do $\mathrm{SNC}$, o que torna imprecisa qualquer tentativa de se atribuir algum valor de localização ao elemento espástico. Um dos primeiros autores a levantar dúvida sobre a dependência do fenômeno espástico de lesão piramidal circunscrita foi Austregésilo 4 , ao postular que "nas hemiplegias capsulares ordinárias, os estados extrapiramidais complicam as lesões piramidais e que a contratura ou a hipertonia é mista, ou seja, pirâmido-extrapiramidal". Essa linha de raciocínio, trilhada pela fisiologia experimental nos anos subsequientes, demonstrou a validade do postulado de Austregésilo para várias espécies de animais, acabando por conquistar aceitação geral para a interpretação de casos clínicos, a despeito do número crescente de evidências contrárias, concomitantemente reportadas na literatura neurológica especializada. 
Julgamos que os casos clinicos a serem relatados possam oferecer alguma contribuiçăo para a elucidaçăo do problema.

\section{OBSERVAÇŌES}

Caso 1 - MCP, uma enfermeira de 59 anos de idade, portadora de hipertensão arterial de longa data, tratada de modo irregular, com níveis sistólicos relatados de 170 a $190 \mathrm{mmHg}$, foi internada com hemiplegia direita, que se instalara na manhã daquele dia, de modo progressivo e saltatório. No oitavo dia de internação, o exame neurológico revelou hemiplegia direita com preservação da face e da articulação-fonação, acompanhada de hiperreflexia muscular, reflexo patẹlar policinético, clônus do pé e hipertonia espástica nos membros, de d1stribuição predominantemente flexora no membro superior e extensora no inferior, acentuada pela deambulação, configurando a atitude hemiplégica de Wernicke-Mann. Os movimentos oculares eram amplos e, à protrusão, a língua apontava para a direita. o reflexo plantar fornecia resposta em flexão a esquerda e em extensåo a direita, acompanhando-se de abertura em leque dos outros artelhos. Não se registravam alteraçōes visuais, auditivas ou mentais e as sensibilidades de posição segmentar, vibratória, ao contato e termo-algésica estavam intactas. Havia sinais eletrocardiográftcos de hipertrofia das câmaras esquerdas e a pressăo arterial se encontrava em 210x120 mmHg. Os outros exames laboratoriais năo apresentavam alterações. Cinco meses depois do ictus persistia, ainda mais evidente, a hemiplegia espástica pura a direita. A face mantinha-se simétrica em repouso e sob contração forçada ou emocional. A IIngua não mais exibia o desvio anteriormente notado. Articulaçăo, fonaçāo e deglutição eram normais. O braço era mantido em ligeira rotaçăo externa, com afastamento do cotovelo do tronco. A palma da mão mantinha-se voltada para dentro, dada a pronação permanente do antebraco e os dedos permaneciam com a primeira falange em extensão e as demais, em flexão. A marcha era dificultada pela intensa hipertonia adutora da coxa, pela ausência dos movimentos normais de flexão do membro inferior acometido durante a progressãa e pela aboliçăo dos reflexos de endireitamento do dimídio direito, com acentuada perturbação do equilibrio. A tentativa de desfazer tais atitudes encontrava resistência apreciável, menor nos dedos da mão e do pé. Essa resistência era proporcional à brusquidăo com que se afastavam os respectivos segmentos e podia ser vencida após etapa preliminar, na qual era máxima (sinal do canivete). Caso o segmento fosse manipulado lentamente, a oposiçåo ao deslocamento diminuia e levava mais tempo para se manifestar. Todavia, o grau de hipertonia era tão intenso que, mesmo em repouso, os músculos mostravam-se contraturados à palpação. Os reflexos musculares deste lado eram extremamente ativos $(6+/ 6+)$ e policinéticos, com irradiação da resposta reflexa para agrupamentos musculares vizinhos e distantes. Havia sinal de Hoffmann e clônus, esgotável na mão e inesgotável no pé e na rótula. $O$ sado são também exibia reflexos hiperativos (embora năo tanto quanto os do lado atingido) e clônus do pé ocasional. Os movimentos realizados sob comando do examinador no lado hemiplégico eram possiveis, principalmente no terço proximal dos membros, sendo prejudicados pela contratura. A pesquisa dos potenciais evocados sômato-sensitivos dos quatro membros não revelou alteracões significativas de forma, velocidade ou latência. A TC de crânio (Fig. 1) evidenciou imagem hipodensa de dimensões lacunares, ocupando o braço posterior da cápsula interna, estendendo-se, verticalmente, por dois planos transversos na altura do tảlamo e do corpo caloso, respectivamente (niveis ventricular baixo e alto (sis). Dois anos depois do início dos sintomas, o quadro neurológico permanece inalterado.

Caso 2 - LFS, um homem de 27 anos de idade, preto, recebera o diagnóstico de anemia falciforme e síndrome de Marfan há 7 e 10 anos, respectivamente. Dois meses antes da internaçăo, deram início às suas queixas artralgia e emagrecimento; 45 dias depois, acusou o aparecimento de febre e mialgia generalizada. Na semana da internação, acordou um dia pela manha impossibilitado de «mexer o lado esquerdo do corpo». Procurou facultativo, que realizou punçāo lombar para exame de líqüudo céfalo-raquidiano, obtendo valores normais. Não se obtiveram evidências de envolvimento com drogas e práticas homossexuais. $O$ exame de internação encontrou o paciente orientado e acordado, com déficit motor no dimídio corporal esquerdo, febril, acianótico e anictérico, dispneico (frequiência respiratória de 29 incursões por minuto) e niveis tensionais de $120 \times 50 \mathrm{mmHg}$. O ritmo cardíaco era irregular, devido a fibrilação atrial de alta freqüência $(180 \mathrm{bpm})$, confirmada ao ECG. O hemograma era compatível a infecção aguda (27 mil leucócitos, $0 \%$ eosinófilos, $4 \%$ bastôes e $86 \%$ segmentados) e as dosagens séricas de enzimas (transaminases, LDH e CPK total e fraçāo MB) encontravam-se dentro da normalidade. Em três amostras para hemocultura, houve crescimento de Streptococcus viridans. O ecocardiograma modo-M visualizou regurgitação aórtica, sem prejuizo hemodinâmico significativo. O ecocardiograma bidimensional revelou hipertrofia concêntrica de VE e prolapso da mitral, com vegetaçōes no folheto posterior. $O$ 
exame oftalmológico com lámpada-de-fenda estabeleceu a presença de ectopia do cristalino. A recuperação clínica com normalização dos exames laboratoriais foi alcançada após 30 día de tratamento - 30 milhões de UI de penicilina cristalina/dia e $1 \mathrm{~g}$ de estreptomicina/dia. Recebeu alta hospitalar no $47^{\circ}$ dia de internação. A hemiparesia se manteve estável durante todo o período hospitalar e não se modifícou até o presente, 9 meses depois do ictus. Quando fala, ri ou abre a boca sob comando, a face torna-se assimétrica, evidenciando paresia a esquerda, predominando na metade inferior e acometendo, em menor grau, o orbicular do olho, deixando intacto o frontal. Movimentos oculares intactos. Pupilas isocóricas e fotorreagentes, reflexo de acomodação presente. Articulação, fonação e deglutição preservadas. Língua sem desvio ou atrofia. Desde os primeiros dias, a hemiparesia impôs à postura ortostática o padrão da atitude de Wernicke-Mann, indicando a instalaçăo precoce da hipertonia espástica, preferencialmente distribuída nos flexores do membro superior - hiperaduzido no braco e hiperpronado no antebraço - e nos extensores e adutores do membro inferior, à qual se adiciona, durante a locomoção, atividade exagerada dos abdutores da coxa, responsáveis pelo caráter ceifante da marcha, decorrente da readaptaçâo funcional utilizada para vencer a espasticidade adutora. A palpação, os músculos do lado acometido mostram-se contraturados. Reflexos musculares universalmente hiperativos, ainda que mais, nos membros esquerdos. Clônus inesgotável do pé esquerdo. Reflexo plantar em flexāo a direita, ocasionalmente em extensão a esquerda, então se associando a extensão e abduçăo dos demais artelhos. Provas de coordenaçăo inalteradas nos 4 membros. Campimetria normal. Sensibilidades de posiçån segmentar, vibratória e termo-algésica normais. Nega parestesias. Estado mental normal. A TC (Fig. 1), realizada com um mês de internaçăo, revelou lesão hipodensa
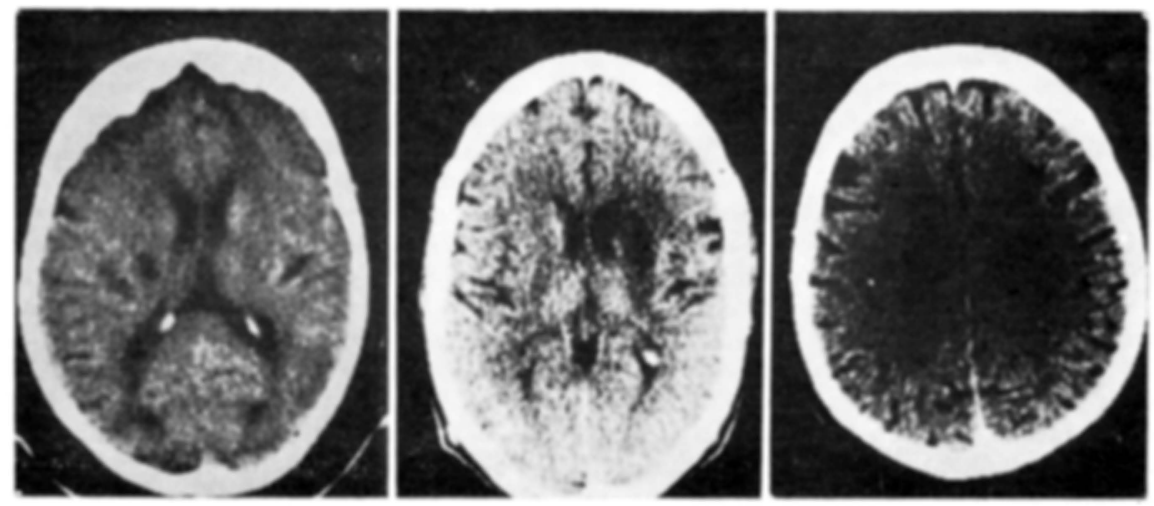

Fig. 1 - Tomografia computadorizada de cranio: à esquerda, caso 1; no meio, axso 2; à direita, caso 3.

subcortical à direita, ocupando a cápsula interna a a coroa radiada, delimitada por dois planos horizontais que atravessam os ventriculos laterais, respectivamente, a nivel do mesencéfalo e do corpo caloso, com formato de lente. O estudo dos potenciais evocados sómato-sensitivos dos 4 membros não revelou quaisquer aiteraçōes.

Caso 3 - AGS, um senhor aposentado com 71 anos de idade foi atendido no comeco de $1987 \mathrm{com}$ queixa de «amortecimento no braço e na perna» esquerdos. Dias antes, pela manhã, sentira, subitamente, «dormência na ponta dos dedos» da mão esquerda, que ascendeu pelo membro e se acompanhou de «inércia». Chamaram-lhe a atenção por estar «alando com a voz baixa». Conduzido ao hospital - onde entrou «cambaleando» — verificaram níveis tensionais de $170 \times 120 \mathrm{mmHg}$, sendo medicado com 1 comprimido sublingual de nifedipina. $A$ noite, a pressão arterial já se havia estabilizado em $120 \times 80 \mathrm{mmHg}$. No dia seguinte, nåo conseguiu levantar da cama, por causa da limitaçåo motora no dimídio esquerdo, que se acentuara significativamente. Além disto, os familiares passaram a sentir dificuldade para compreender o que falava. Acredita ter piorado progressivamente no decorrer da semana seguinte. Não se registraram cefaléia, distúrbios do nivel de consciência ou perda do controle esfincteriano. Negou abuso de álcool, mas disse fumar um maco de cigarros por dia desde os 20 anos de idade. Vinha fazendo uso irregular de propranolol nos últimos 4 meses para tratamento da hipertensāo arterial. Quando visto pela primeira vez, 7 dias depois do inicio dos sintomas, encontrava-se acordado e orientado, sem sinais de irritação meningea. 
Exibia hemiplegia esquerda, proporcional, com discreta resisténcia a extensão passiva do antebraço e da măo e à flexăo passiva da perna, apenas observada no terço final dos movimentos e quando a manobra era executada com rapidez. A face era assimétrica em repouso: năo conseguia manter o olho esquerdo fechado por mais de alguns instantes e a comissura labial se desviava para a direita. A protrusão, a língua apontava para a esquerda. A fala era disártrica e de baixa intensidade, mas não havia disfagia. Os movimentos oculares eram amplos e estavam limitados somente na convergência. As pupilas, isocóricas e fotorreagentes. Quase impossibilitado de elevar o membro superior esquerdo, não movia a mão e os dedos. O membro inferior năo agiuentava o peso do corpo, mas se adiantava a cada passo, se o paciente fosse sustentado para näo cair. A despeito do déficit motor, era possivel constatar presença de dissociação flexora-extensora nos membros atingidos. Os reflexos musculares estavam hiperativos $(4+/ 6+)$ a esquerda e havia clônus esgotável no pé. o reflexo plantar dava resposta em flexăo a direita e em extensão dos 5 artelhos a esquerda, acompanhando-se de retirada em tríplice flexão do membro inferior deste lado. Campimetria $\theta$ audiometria normais. Sensibilidade de posiçăo segmentar, vibratória, ao contato, a nocicepção e a temperatura normais. Ao exame físico, apresentava tórax enfisematoso e bradicardia de $54 \mathrm{bpm}$, ausculta cervical e cardíaca sem alterações e pressăo arterial de $140 \times 80 \mathrm{mmHg}$. $O$ ECG revelou sindrome de pré-excitação ( $\mathrm{PR}=0,10 \mathrm{seg}$ ), 8 a 10 extrassístoles supraventriculares por minuto e bloquelo do lamo direito de $2^{*}$ grau. O hemograma revelou leucometria de 8.800 células $/ \mathrm{mm} 3$, hemoglobina de $14,8 \mathrm{~g} \%$ e hematócrito de 56 . Glicemia, 86 mg\%; uréia $44 \mathrm{mg} \%$ e creatinina $0,9 \mathrm{mg} \%$. Três meses depois do inicio dos sintomas, apresentava dor e edema na mão esquerda, que tendia a permanecer com os dedos em flexão e a palma voltada para cima, devido a supinaçăo mantida do antebraço. A dcambulação era, agora, favorecida pelo ressurgimento de tônus nos músculos do membro inferior, coincidente a aumento da espasticidade nos agrupamentos em que, antes, era apenas perceptível e, também, com o advento da atitude de Wernicke-Mann, quando se punha em pé ou caminhava. A espasticldade era maior no membro superior e se acentuava com o movimento voluntário, interferindo na sua realização. $O$ déficit motor, propriamente, reduziu-se e somente podia ser evidenciado nas manobras de Mingazzini e Barré. No membro superior, os músculos mostravam-se discretamente contraturados à palpaçăo. Embora a face continuasse assimétrica, a lingua não mais se desviava e a articulação da fala era quase normal. Obtinham-se, com facilidade, sinal de Babinski, hiperreflexia muscular $(6+/ 6+)$ e clónus do pé, a esquerda. Queixava-se de «dormência» ocasional, em uma área circunscrita do mento, a esquerda. $O$ exame da sensibilidade continuava normal, inclusive na área de parestesia mentoniana. Cinco meses depois do ictus, era capaz, apenas, de esbocar movimentos de flexão dos dedos da mão, ainda paralisada e edemaciada. Não mais sentia a dormência no mento. A espasticidade predominava nos movimentos voluntários e, à palpação, os músculos não mais se encontravam contraturados. A prova calcanhar-joelho, agora possível do lado comprometido, estava normal. A TC de crânio (Fig. 1), realizada um mês e meio após o aparecimento dos sintomas, revelou acentuação dos sulcos corticais e área subcortical hipodensa, ocupando os lobos frontal (nivel ventricular alto) e parietal (nivel supraventricular) (3n). Os potenciais evocados sômato-sensitivos não apresentavam alteraçôes de forma, velocidade ou latência. Durante o perfodo de acompanhamento, foi medicado com hipotensores leves $e$ antiinflamatórios.

\section{COMENTARIOS}

1. Hemiplegia espástica pura e afeç̧ão cerebrovascular - No primeiro pacientt, o infarto lacunar observado à TC coincide com o tipo mais comum, detectado na cápsula interna de pacientes com HMP 03. Suas dimensões e forma arredondada, incluem-no no padrāo da lacuna típica, restrita à cápsula interna e preservando as massas nucleares vizinhas. A ausência de anormalidade, nos potenciais evocados sômato-sensitivos, valida a impressão clínica de inexistência de comprometimento sensitivo 16. A lesão isquêmica, provavelmente ocasionada por trombose (instalação aguda, progressão saltatória) da artéria coróide anterior 36 se alojou caprichosamente, ao que tudo indica, sobre o feixe piramidal em sua passagem através do braço posterior da cápsula interna 21,42 aí 0 interrompendo sem, aparentemente, danificar núcleos ou vias de projeção adjacentes. Os achados semiológicos do caso 2 são idênticos aos do anterior. As características da lseão notada à TC diferem em aspectos essenciais. Com formato de lente nos cortes transversais, o infarto excede as dimensões de uma lacuna e ocupa cerca de $3 \mathrm{~cm}$ no sentido vertical, destruindo o joelho, o braço posterior da cápsula interna e parte dos núcleos da base. A irrigação deste território depende dos ramos corticais (insulares) e profundos (lentículo-estriados, em especial os laterais) 
da artéria cerebral média, o que o torna muito suscetivel à isquemia, por situar-se em zona limitrofe 8 . Seu envolvimento é revelador de oclusão da carótida interna, depois da emergência da coróide anterior, na altura do ponto de origem da cerebral média. Como, muitas vezes, a circulação colateral de suplência é eficaz para manter fluxo adequado nos ramos corticais, a região de isquemia máxima freqüentemente se restringe a dos núcleos da base, como em nosso paciente. Presumivelmente, a afecção cardiaca da doença de Marfan propiciou a colonização da lesão orovalvular pelo estreptococo e o desenvolvimento subsequiente de endocardite e embolia cerebral. Como no caso anterior, a inexistência de alterações nos potenciais evocados sômato-sensitivos, indica que as vias somestésicas não foram atingidas. No terceiro paciente, os achados tomográficos assemelham-se aos do caso precedente. Nele, porém, o infarto tem situação mais alta, sugerindo dever-se a insuficiência circulatória local, da zona limitrofe dos territórios das artérias cerebral anterior (paracentral) e média (parietal posterior) ${ }^{\mathbf{9}, 19}$. O estudo dos potenciais evocados sômato-sensitivos novamente afasta a ocorrência de comprometimento relevante das vias aferentes somestésicas. A figura 2 oferece visão esquemática da superfície lateral dos hemisférios cerebrais e as respectivas projeções, com base em cortes tomográficos, da cápsula interna e dos infartos observados nos três pacientes que acabamos de apresentar.

II. O elemento espástico da sindrome piramidal humana - Conforme assinalamos na introduçāo, parece hoje demonstrado que o elemento motor deficitário, a hiperrreflexia muscular e o sinal de Babinski das hemiplegias cruzadas, se correla-

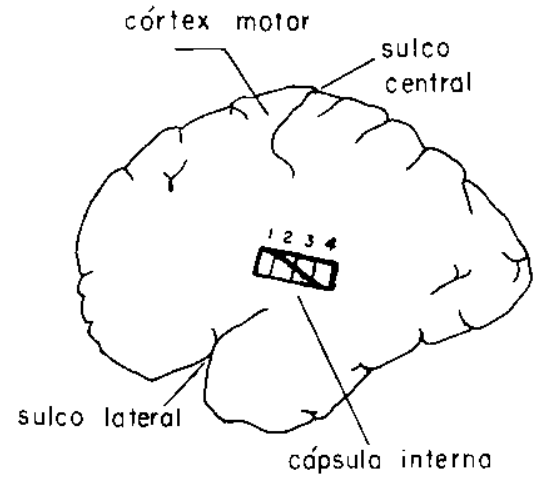

(braço posterior) e

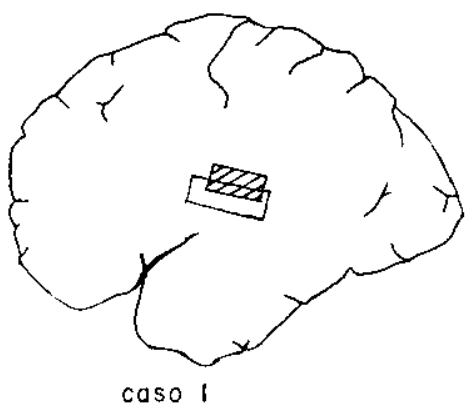

feixe piramidal.

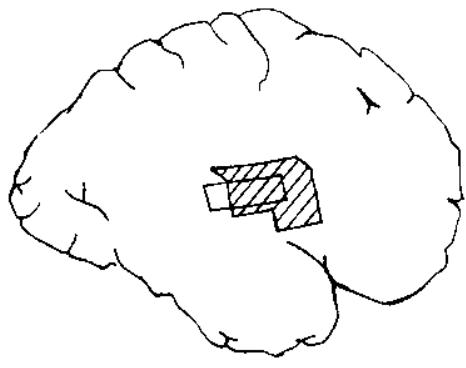

$\cos 02$

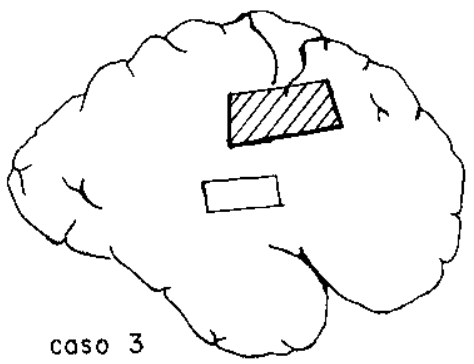

WIIA - área de infarto

Fig. 2 - Face lateral dos hemisférios cerebrais. Reconstrução esquemalica da posiçāo do feixe piramidal no braco posterior da câpsula interna $e$ sua relaça com os infartos observodos nos pacientes, com base nus imagens tomograficas. 
cionam diretamente com uma afecção do feixe piramidal. Aparentemente, a principal dúvida reside no significado da espasticidade. A despeito das controvérsias conceituais e semânticas que o envolvem, o termo "espasticidade" guarda significado operacional preciso para o clínico e sua presença pode ser semiotecnicamente testada 1,32,49,60. Refere-se a tipo peculiar de resistência exibida por determinados agrupamentos musculares de segmentos paréticos ou paralisados - tipicamente representados pelos adutores da coxa, extensores da perna e dorsiflexores do pé e dos artelhos e pelos adutores do braço, flexores do antebraço e da mão e dos dedos - quando submetidos a manipulação passiva. Esta oposição ao movimento, nos graus de pequena intensidade, se nos apresenta como súbita resistência ao deslocamento (espasmo 4) que, quase de repente, atinge o máximo de intensidade para logo em seguida ceder, permitindo a manipulação livre do segmento do corpo. $O$ fenômeno, alegoricamente conhecido como sinal do canivete, e peculiar e volta a ocorrer, desde que se deixe repousar por alguns instantes o membro onde tenha sido observado. A fase de oposiçäo inicial é tanto mais precoce e intensa quanto mais rapidamente se efetue a manipulação. Em condições nas quais este fenômeno é muito intenso, os membros são mantidos em posiçoes relativamente fixas, representadas globalmente na atitude de Wernicke-Mann, devido a atividade muscular continua que, à palpação, transmite a impressăo de enrijecimento ou contratura dos músculos 49 . Frequientemente, nos segmentos espásticos coexistem hiperreflexia muscular e clônus, do pé, da rótula ou da mão. Segundo Adams e Victor 1, "a característica essencial da espasticidade é uma reatividade (muscular) aumentada para um estimulo de estiramento", fenomeno este comprovado inúmeras vezes por investigações eletromiográficas 58. Quando se aborda o fenômeno espástico, deve-se enfatizar que sua ocorrência indica, essencialmente, modificação patológica qualitativa do tônus dos músculos acometidos. Isto implica que sua distribuição somática — compare-se, por exemplo, a espasticidade da atitude hemiplégica de Wernicke-Mann com a da paraplegia espástica da doença de Little não é essencial para conceituar sua existência. De igual modo, o clínico não precisa aguardar estados de espasticidade pura para diagnosticá-la pois, na prática diária, as lesões capazes de produzi-la podem ser suficientemente extensas para acarretarem distúrbios associados do tônus muscular de natureza obviamente distinta, como é o caso, por exemplo, da atetose pós-hemiplégica 26 . Com base nos casos apresentados, nos quais observamos lesões relativamente isoladas, porém extensas, dos feixes piramidais, desejamos enfatizar que, de igual modo, à ocorrência de espasticidade, deve-se atributir valor de localização fortemente sugestivo de alterações patológicas do feixe piramidal. $\mathrm{Na}$ realidade, essa idéia não é nova. No início do século atual, já havia se incorporado ao "Zeitgeist" clínico 22, previamente formulado por diversos autores que, durante a última metade do século 19 , documentaram inúmeros casos de pacientes que, em vida, exibiam a triade clinica de paresia, hiperreflexia e espasticidade e em cujos cérebros, à necrópsia, verificavam presença de degeneração e gliose dos feixes piramidais e, eventualmente, atrofia da circunvolução precentral \%,10,14,15,28,41,47,57. Acompanhando o trajeto da gliose, observaram que decussava — em proporçōes que variavam de um individuo a outro - para o lado oposto da medula espinhal, imediatamente abaixo das pirâmides bulbares. Portanto, o conceito anatômico de feixe piramidal e o clínico, de sindrome piramidal, são indissociáveis, um devendo sua origem ao outro. Em 1898, Babinski 5 acrescentou o quarto e último elemento fundamental para a caracterização formal da síndrome. Um fator adicional, todavia, tem confundido a questão e, aparentemente, refutado os fundamentos do enunciado anterior. Referimo-nos às tentativas de aplicação de conceitos baseados em experimentos animais à prática clínica, efetuadas de modo sistemático, desde os trabalhos de Sherrington até o presente 25. Sem que nos detenhamos em revisão extensa, basta sublinhar a conclusão geral desses autores, de que a síndrome piramidal resulta da lesão de vias e centros anatômicos, distintos do feixe piramidal, uma vez que a secção experimental deste feixe, seja em que altura for, não se acompanha de manifestações comparáveis às classicamente descritas na clinica. Vias justapiramidais, parapiramidais e outras foram invocadas como explicação, em especial, para o aparecimento da espasticidade. Acreditamos que nenhuma dessas hipóteses se apliquem integralmente ao ser humano. Em primeiro lugar - e este dado nos é fornecido por fisiologistas especializados no assunto - jamais se conseguiu reproduzir o fenômeno espástico em animais, tal qual se apresenta no homem 64,65. Em segundo, o feixe piramidal no ser humano possui organização própria e distintiva, não existindo como tal em qualquer outra espécie animal, incluindo simios 2. Finalmente, se nos utilizarmos da própria observação em pacientes para controlar e demonstrar o argumento anátomo-clínico, veremos que os 4 principais elementos que integram a sindronie piramidal 
estão habitualmente presentes nos casos em que os dois ou somente um dos feixes piramidais se encontram comprometidos por processos patológicos das mais variadas naturezas, na medula espinhal 23 , no bulbo $18,20,39,45,46,48,55,59$, na protuberância 13,24 na transição pontopeduncular 50 , no pedúnculo cerebral 38 , na cápsula interna 27,35 ou no córtex cerebral (precentral)17,62. Em todos os casos, dos acima referidos, nos quais foi possivel a realização de necrópsia e o estudo dos efeitos à distância da lesão primária, invariavelmente constatou-se a ocorrência de degeneração secunđária conspicua, exclusiva ou predominantemente, dos feixes piramidais, principalmente do lateral. Assim, considerando que $(a)$ do córtex cerebral à medula espinhal, a única estrutura nervosa de ocorrência constante é o feixe piramidal e que $(b)$ lesōes isoladas, em pacientes diferentes, sediadas em qualquer altura do SNC - do córtex cerebral à medula espinhal - podem manifestar-se por paresia, hiperreflexia muscular, espasticidade e sinal de Babinski, torna-se evidente o papel da lesão do mencionado feixe como responsável pela produção desses sintomas. Esta idéia é reforçada pelo fato de que, por sua vez, a síndrome só ocorrerá se a lesão comprometer direta ou indiretamente a área por onde trafegam as fibras piramidais, conforme assinalado na introdução deste estudo. A literatura contemporânea freqüentemente nos oferece exemplos de casos congruentes com as noções anátomo-clínicas do século passado e atual. Em 1973, Trelles et al.59 reuniram 11 casos em que verificaram a ocorrência de síndrome piramidal, conforme acima caracterizada, produzida, em sua maioria, por afecções cerebrovasculares isquêmicas, que haviam destruido um ou ambos os feixes piramidais na altura da protuberância ou do bulbo. Nove desses pacientes apresentaram espasticidade acompanhando a paralisia; um deles faleceu antes do prazo natural para o seu surgimento e um outro não a desenvolveu até morrer, 10 meses depois. Mais uma vez, a demonstração de que a síndrome piramidal se deve, de fato, à lesão desses feixes, foi recentemente fornecida por Fisher 29 e Flint Beal e Richardson 31. Esses autores acompanharam pacientes tetraparéticos, gravemente disfônicos, disfágicos e disártricos, manifestando episódios de choro e riso espasmódicos, hiperreflexia muscular, espasticidade e sinal de Babinski bilateral, nos quais foi encontrada atrofia bilateral das circunvoluções precentrais e rarefação celular das camadas III e V; todo o traieto dos feixes córtico-espinhais, Iaterais e anteriores, encontrava-se degenerado e gliótico. Os demajs sistemas anatômicos de fibras e núcleos estavam intactos.

III. Implicações para a organização funcional do feixe piramidal no homem O exame dos casos relatados no presente trabalho, permite-nos afirmar que os três pacientes apresentam sindromes piramidais completas. Ao contrário do que acontece em animais de experimentação submetidos à ablação cirúrgica do córtex dos hemisférios cerebrais 61 , a síndrome motora que se instala em pacientes humanos hemisferectomizados 53 é idêntica a que observamos em nossos pacientes. Esta comparação parece demonstrativa do significado dos feixes piramidais como principal via de efetuação suprassegmentar no homem, conceito este sucintamente discutido alhures 34 . Por outro lado, cada um dos 4 elementos da síndrome piramidal pode ocorrer independente dos demais. Em nossa opinião, a possibilidade de ocorrência deste fato, reflete a delicada heterogeneidade funcional e anatômica dos fascículos nervosos que se agrupam no feixe piramidal. O anarecimento de sindrome piramidal completa em casos de mielopatia transversa total $\mathbf{5 2}$ demonstra que os sinais de liberação (hiperreflexia, espasticidade e sinal de Babinski) têm origem segmentar 51 e, além disto, que 0 alvo de regulação piramidal é eminentemente segmentar. Estudos recentes demonstram que o córtex motor humano é constituido de tipos neuronais de formas e dimensões variadas 44 , dispostos espacialmente em colunas de orientação vertical. Cada tipo celular recebe aferentes de regiōes corticais e subcorticais definidas e, por sua vez, emite conexöes para áreas vizinhas e distantes, igualmente especificas. Em primatas não humanos, os tipos celulares que dāo origem aos axônios que constituem os feixes piramidais estão hoje bem determinados. Provavelmente, neste caso, os mesmos princípios gerais se apliquem, também, ao ser humano 44 . Com base nessas consideraçóes, talvez o conceito que melhor se aịuste aos dados clínicos e anatômicos de que dispomos seia o de que o sistema piramidal atue, princinalmente, por intermédio de um "controle diferencial", exercido sobre alvos segmentares distintos $e$ especificos. Admitindo ( $a$ ) a semelhanca entre a hemiplegia da hemisferectomia total e a ocasionada por lesão piramidal restrita e $(b)$ que o córtex precentral é o principal alvo de projeçốes - via tálamo - dos núcleos da base e do cerebelo 3 , parece-nos lícita a conclusão de que os feixes piramidais representam a principal via pela qual encontra expressão comportamental, em determinado instante, a maior parte da atividade funcional resultante da integração cérebro-cerebelar. 
Aparentemente, essas conclusōes somente se aplicam integralmente ao homem. Os conceitos de sistema ou feixe piramidal devem ser qualificados quanto a espécie animal particular em discussão. Comparações que não respeitem as diferenças interespecificas certamente contribuirão para confundir a questão e turvar a clareza de um dos mais belos conceitos nascidos do esforço comum da biologia e da clínica médica para melhor compreender os enigmas do cérebro humano.

Agradecimentos - Desejamos expressar nosso agradecimfnto a prestimoza colaboraçăo dos Drs. Rogerio José dos Reis, Denise Nicaretta Hack, Levi Inimá de Miranda e Marcelo Heitor Mendes, no acompanhamento dos pacientes apresentados no presente trabalho. Estamos em débito com o Sr. José Manoel da Costa, que fez as ilustrações.

\section{REFERENCIAS}

1. Adams RD, Victor M - Principles of Neurology. Ed. 3. McGraw-Hill, New York, 1985.

2. Armand J - La voie pyramidale. Rev Neurol (Paris) 140:309, 1984.

3. Asanuma C, Thach WT, Jones EG - Distribution of cerebcllar terminations and their relation to other afferent terminations in the ventral lateral thalamic region of the monkey. Brain Res Rev 5:237, 1983.

4. Austregésilo AM - La contracture de l'hémiplégle dite capsulaire est pyramido-extrapyramidale. Encéphale 1:1, 1928.

5. Babinski J - Du phénomène des orteils et de sa valeur sémiologique. In Oevre Scientifique. Masson, Paris, 1934.

6. Barré J-A $\rightarrow$ Le syndrome pyramidale déficitaire. Rev Neurol (Paris) 67:1, 1937.

7. Bennett $\mathrm{AH}-$ Muscular hypertonicity in paralysis. Brain 10:289, 1888.

8. Bladin PF, Berkovic SF - Strlatocapsular infarction: large infarcts in the lenticulostriate arterial territory. Neurology $34: 1423,1984$.

9. Bogousslavski J, Regli $\mathbf{F}-$ Borderzone infarctions distal to internal carotid artery occlusion: prognostic implications. Ann Neurol 20:346, 1986.

10. Bouchard $\mathrm{C}$ - Des dégénérations secondaires de la moella épinière. Arch Gén Méd (Paris), VI sér, 8:273, 1866.

11. Brion S, Guiot G - Topographie des faisceaux de projection du cortex dans la capsule interne et dans le pédoncule cérébral. Rev Neurol (Paris) 110:123, 1964.

12. Brion $\mathrm{S}$, Plas $\mathrm{J} \rightarrow$ Les lésions du cortex moteur dans la sclérose latérale amyotrophique. L'Encéphale 12:81, 1986.

13. Brown WC, Fang HC - Spactic hemiplegia in man. Neurology 9:829, 1961.

14. Charcot $\mathrm{IM}$ - Du faisceaux pyramidal dans les pédoncules cérébraux, la capsule interne et le centre ovale. Prog Méd 7:557, 1879.

15. Charcot JM, Joffroy A - Deux cas d'atrophle musculaire progressive avec lésions de la substance grise et des faisceaux antéro-latéraux de la moelle épinière. Arch Phys Norm Pathol (Paris) 2:745, 1869.

16. Chokroverty S, Rubino FA - Pure motor hemiplegia. I Neurol Neurosurg Psychiat $38: 896,1975$.

17. Chokroverty S, Rubino FA, Haller C - Pure motor hemiplegia due to cerebral cortical infarction. Arch Neurol 34:93, 1977.

18. Currier RD - The medial medullary syndrome. J Univ Mich Med Cen 42:96, 1976.

19. Damasio $\mathbf{H}$ - A computed tomographic guide to the identification of cerebral vascular territories. Arch Neurol 40:138, 1985.

20. Davison C - Syndrome of the anterior spinal artery of the medulla oblongata. $J$ Neuropathol Exp Neurol 3:73, 1944.

21. Decroix JP, Cambier J, Magson M - Le syndrome de l'artère choroidienne anterieure. Presse Méd 14:1085, 1985.

22. Déjérine J - Sémlologie des Affections du Système Nerveux. Masson, Paris, 1914.

23. Déjérine J, Sottas J - Notes sur un cas de paraplégie spasmodique acquise, par sclérose primitive des cordons latéraux. C $\mathbf{R}$ Soc Biol 2, 10me sér: 776, 1895.

24. De Meyer W, Ross AT - The syndrome of complete interruption of corticospinal tract in the brainstem of man. Trans Am Neurol Ass 84:18, 1959.

25. Denny-Brown D - The Cerebral Control of Movement. Liverpool UP, Liverpool, 1966.

26. Dooling EC, Adams RD - The pathological anatomy of the post-hemiplegic athetosis. Brain 98:29, 1975 .

27. Englander RN, Netsky MG, Adelman Ls - Location of the human pyramidal tract in the internal capsule: anatomical evidence. Neurology 25:823, 1975. 
28. Erb W - Ueber elnen wenig bekannten spinalen Symptomen-complex. Berl Klin Wchnsch 26:357, 1875.

29. Fisher CM - Pure spastic paralysis of cortico-spinal origin. J Can Sci Neurol 4:251, 1977.

30. Fisher CM, Curry HB - Pure motor hemiplegia of vascular origin. Arch Neurol 13:30, 1965.

31. Flint Beal M, Richardson EP - Primary lateral sclerosis. Arch Neurol 38:630, 1981.

32. Foix C, Chavany J-A -- Sur la contracture pyramidale envisagé dans ses rapports avec les autres contractures. Presse Méd 2:629, 1924.

33. Gado M, Hanaway J, Frank R - Functional anatomy of the cerebral cortex by computed tomography. J Comp Assist Tomogr 3:1, 1979.

34. Gusmão DL, Duarte ACG, Oliveira Souza $R-$ Sindrome do cativeiro («locked-in syndrome»): apresentaçāo de caso clínico. VI Jornada do Hospital de Clínicas Gaffrée e Guinle; Rio de Janeiro, 5 a 8 de novembro de 1984.

35. Hanaway J, Young RR - Localization of the pyramidal tract in the internal capsule of man. J Neurol Sci 34:67, 1977.

36. Heigason C, Caplan LR, Goodwin J, Hedges $\mathbf{T}$ - Anterior choroidal artery-territory infarction: report of cases and review. Arch Neurol 43:681, 1986.

37. Hirayama $\mathbf{K}$, Tsubaki $\mathbf{K}$, Toyokura $\mathbf{Y}$, Okinaka $\mathbf{S} \rightarrow$ The representation of the pyramidal tract in the internal capsule and basis pedunculi. Neurology 12:337, 1962.

38. Ho K-L - Pure motor hemiplegia due to infarction of the cerebral peduncle. Arch Neurol $39: 524,1982$.

39. Ho K-L, Meyer KL - The medial medullary syndrome. Arch Neurol 38:385, 1981.

40. Kashihara $\mathbf{M}$, Matsumoto $\mathbf{K}$ - Acute capsular infarction: location of the lesions and the clinical features. Neuroradiol $27: 248,1985$.

41. Kojewnikoff A - Cas d'esclérose latérale amyotrophique, la dégénération des faisceaux pyramidaux se propageant a travers tout l'encéphale. Arch Neurol (Paris) 6:356, 1883.

42. Lazzarino LG, Nicolai A - Infarctus de l'artère choroïdiene antérieure révélé par une hémiplégie motrice pure. Presse Méd 16:1004, 1987.

43. Manelfe C, Clanet M, Gtgaud M, Bonafé A, Guiraud B, Rascol A - Internal capsule: normal anatomy and ischemic changes demonstrated by computed tomography. Amer $\mathrm{J}$ Neuroradiol 2:149, 1981.

44. Meyer G - Forms and special arrangements of neurons in the primary motor cortex of man. J Comp Neurol 262:402, 1987.

45. Meyer JS, Herndon RM - Bilateral infarction of the pyramidal tracts in man. Neurology $12: 637,1962$.

46. Mizutani $T$, Lewis RA, Gonatas NK - Medial medullary syndrome in a drug abuser. Arch Neurol $37: 425,1980$.

47. Mott FW - A case of amyotrophic lateral sclerosis with degeneration of the motor path from the cortex to the periphery. Brain 18:21, 1895.

48. Nardelli E, Ianucci A, Rizzuto $\mathbf{N}$ - Bilateral infarction of the pyramidal tracts. Arch Neurol 33:130, 1978.

49. Noïca D - Comment devons-nous définir la contracture? Rev Neurol (Paris) 1:218, 1911.

50. Oliveira Souza R, Esbérard CA - Síndrome de encarceramento: análise fisiopatologica de dois casos. Rev Bras Neurol 21:11, 1985.

51. Pierrot-Deseilligny E, Mazieres L - Spinal Mechanisms Underlying Spasticity. In Delwaide PJ, Young RR (eds): Clinical Neurophysiology in Spasticity. Elsevier, Amsterdam, 1985.

52. Pollock LJ - Spasticity, pseudospontaneous spasms, and other reflex activities late after injury to the spinal cord. Arch Neurol Psychiat 66:537, 1951.

53. Ralston BL - Hemispherectomy and hemithalamectomy in man. J Neurosurg 19:909, 1962.

54. Rascol A, Clanet M, Manelfe C, Guiraud B, Bonafe A - Pure motor hemiplegia: CT study of 30 cases. Stroke 13:11, 1982.

55. Ropper AH, Fisher CM, KIeinman CM - Pyramidal infarction in the medulla: a cause of pire motor hemiplegia sparing the face. Neurology 29:91, 1979.

56. Ross ED - Localization of the human pyramidal tract in the internal capsule by whole brain dissection. Neurology 30:59, 1980.

57. Strümpell A - Ueber einen Fall von primärer systematischer Degeneration der Pyramidenbahnen mit der Symptomen einer allgemeinen spatischen Lähmung. Deuts $\mathbf{Z}$ Nervenheil $3: 225,1894$.

58. Thiébaut F, Isch F, Isch-Treussard $\mathbf{C}$ - Contribuition à l'étude des contractures d'origine centrale: étude clinique et électromyographique des muscles au repos, a la mobilisation active et a la mobillsation passive. Rev Neurol (Paris) 94:209, 1956. 
59. Trelles $\mathrm{J}-\mathrm{O}$, Trelles $\mathrm{L}$, Urquiaga $\mathrm{C}$ - La spasticité dans l'hémiplégie par léstons de la pyramide bulbaire. Rev Neurol (Paris) 129:105, 1973.

60. Twitchell TE - The restoration of motor function following hemiplegia in man. Brain $74: 443,1951$.

61. Walker AE, FuIton JF - Hemidecortication in chimpanzee, baboon, macaque, potto and coati: a study in encephalization. J Nerv Ment Dis 87:677, 1938.

62. Weintraub MI, Glaser GH - Nocardial brain abcess and pure motor hemiplegia. New York St J Med 70:2717, 1970.

63. Weisberg LA - Computed tomography and pure motor hemiplegia. Neurology 29:490, 1979.

64. Wiesendanger $M$ - Is There An Animal Model of Spasticity? In Delwaide PJ, Young RR (eds): Clinical Neurophysiology in Spasticity. Elsevier, Amsterdam, 1985.

65. Wiesendanger $\mathbf{M}-$ Animal Models of Motor Disorders. In Struppler A, Weindl, A: Electromyography and Evoked Potentials. Springer, Berlin, 1985. 